Graham H. McMorland MB CH B FRCPC, Leonard C. Jenkins MD CM FRCPC, M. Joanne Douglas MD FRCPC

\title{
A survey of obstetric anaesthesia practice in British Columbia
}

Hospitals and anaesthetists in British Columbia were surveyed by means of questionnaires to assess patterns of obstetric anaesthesia practice, qualifications and numbers of obstetric anaesthesia personnel, hospital obstetric facilities and facilities and protocols for neonatal resuscitation.

It was apparent that a large proportion of the obstetric anaesthesia service in this province was being provided by physicians who were not trained, nor certified, as anaesthesia specialists.

Preanaesthetic assessment in the obstetric units differed in attitude and practice from the standards expected in the general operating rooms. There was also in community hospitals a significant incidence of failure to follow certain accepted safe practices (in obstetric patients), such as preinduction hydration and oxygenation, cricoid pressure during intubation and prevention of aortocaval compression. However, administration of general anaesthesia without endotracheal intubation, was rare in this survey.

Post-anaesthetic recovery facilities in obstetric units were conspicuously deficient, even in the larger hospitals.

The majority of community hospitals lacked written protocols for neonatal resuscitation; and the number of institutions reporting that the neonatal heart rates and temperatures were not routinely monitored is of concern.

It is recommended that minimum standards for training in abstetric anaesthesia should be clearly defined; and provision should be made for revision and upgrading of knowledge and skills for physicians practicing anaesthesia in smaller community hospitals.

\section{Key words}

ANAESTHESIA, obstetric.

From the Department of Anaesthesia, University of British Columbia and Grace Hospital, Vancouver, B.C.

Address correspondence to: Dr. G.H. McMorland, Department of Anaesthesia, Grace Hospital, 4490 Oak Street, Vancouver, B.C. V6H 3V5.
A number of reports published in recent years have raised concerns regarding standards of practice in obstetric anaesthesia. ${ }^{1-3}$ It has been suggested that these areas of concern may have been related to deficiencies in anaesthesia resident training programmes. ${ }^{1,2}$ Certainly our previous survey was able to identify such deficiencies in some Canadian programmes. $^{2}$

Much attention has been directed at regionalization of medical services with establishment of regional referral centres. However, the geographic realities in Canada are such that there are many small, often remotely situated, hospitals each having a small obstetric case-load. These small units frequently lack certain facilities, have little (if any) access to specialty consultations and may even be isolated during the winter season (making transportation of patients to referral centres difficult). Anaesthesia is often provided by nonspecialist physicians who may not have been specificially trained in obstetric anaesthesia and/or have too small a case-load to develop and retain their skills adequately.

This survey was undertaken to assess patterns of practice, qualifications and numbers of obstetric anaesthesia personnel, as well as hospital obstetric anaesthesia facilities provided in both university-affiliated referral hospitals and smaller community hospitals in British Columbia.

\section{Methods}

In early 1982 a questionnaire was sent to the administrator of each hospital in B.C. known to have maternity beds. An attached letter requested the administrator to have the questionnaire completed by the chief of anaesthesia or chief-of-staff. A different questionnaire was sent to all anaesthetists in British Columbia holding the specialist certification of the Royal College of Physicians of Canada, except those who were known to practice in hospitals without maternity beds. This question- 
naire was also sent to a number of physicians who were not certified as specialists by the Royal College of Physicians of Canada, but who were known to administer anaesthetics in their local hospitals. This latter group was difficult to identify and the list was known to be incomplete.

The questionnaire, sent to the hospitals, requested the following information:

1 The number of physicians practicing anaesthesia on their medical staff and the number who were certified specialists.

2 Details of anaesthesia and resuscitation equipment in each of the labour and delivery rooms.

3 Facilities for accommodating anaesthetists while on duty in the hospital.

4 Presence of an intensive care nursery and immediate availability of a paediatrician.

5 Facilities for post-anaesthetic recovery in the delivery suite.

6 Facilities for pre-anaesthetic consultation and patient education; requirement for signed, informed consent.

7 Percentage of obstetric patients receiving: general anaesthetics; epidural analgesia/anaesthesia; subarachnoid block; inhalation analgesia; other forms of analgesia in labour; routine use of antacids in labour.

8 Incidence, as a percentage of all general anaesthetics administered to obstetric patients, of endotracheal intubation, or anaesthesia via face mask.

9 Routines for neonatal resuscitation.

The questionnaires to physicians requested similar information regarding facilities for anaesthesia, resuscitation and postanaesthetic recovery in their hospitals. They were also asked questions relating to their individual patterns of obstetric anaesthesia practice:

1 Prenatal anaesthesia counselling, visits to patients in labour to discuss analgesia, obtaining informed consent;

2 Personal patterns of practice in providing analgesia/anaesthesia for both vaginal delivery and Caesarean section:

a Use of regional blocks during labour,

b Choice of anaesthesia for Caesarean section (regional or general),

c Measures to prevent pulmonary aspiration of acid gastric contents,
TABLE I Number of hospitals replying to questionnaire

\begin{tabular}{clc}
\hline Number of deliveriesiyear & $\begin{array}{l}\text { University } \\
\text { affiliated }\end{array}$ & $\begin{array}{l}\text { Community } \\
\text { hospitals }\end{array}$ \\
\hline$<100$ & 0 & 8 \\
$101-200$ & 0 & 12 \\
$201-500$ & 0 & 9 \\
$501-1000$ & 0 & 4 \\
$1001-2000$ & 0 & 5 \\
$>2000$ & 3 & 1 \\
\hline
\end{tabular}

TABLE II Physicians practicing anaesthesia in responding hospitals

\begin{tabular}{llr}
\hline & $\begin{array}{l}\text { University } \\
\text { hospitals }\end{array}$ & $\begin{array}{l}\text { Community } \\
\text { hospitals }\end{array}$ \\
\hline Specialists & $62(100 \%)$ & $19(13.4 \%)$ \\
Non-specialists & 0 & $123(86.6 \%)$ \\
\hline
\end{tabular}

d Choice of drugs,

e Prevention and treatment of hypotension;

3 Participation in neonatal resuscitation; personal opinion regarding the ideal role of the anaesthetist in resuscitation of the depressed neonate. Questionnaires were sent to 78 hospitals and replies were received from 42 (53.8 per cent). These replies represented hospitals in all geographic areas of British Columbia. They also included hospitals of varying sizes, with annual delivery rates ranging from less than 100 to over 5000 .

Three of the 42 hospitals were affiliated with the University of B.C. and the other 39 were community hospitals (Table I).

Questionnaires were sent to 92 specialists who practice obstetric anaesthesia and replies were received from 44 (47.8 per cent). An additional 28 questionnaires were sent to non-specialist anaesthetists of whom 13 replied ( 46 per cent). It was felt that this response rate, while small, was expected from busy physicians and was adequate for us to report. We recognise that those who did not reply to the questionnaire may have different patterns of practice which would have affected the reported results. We are not able to assess the possible effect of such "non-response bias."

The replies received from hospitals were tabulated separately from those received from individual physicians. In reporting the results of the 
survey, they will, whenever applicable, be recorded on the same table, for ease of comparison.

\section{Results}

\section{Anaesthesia personnel (Table II)}

One hundred per cent of the obstetric anaesthesia staff in the university-affiliated hospitals had specialty qualifications, while the majority of anaesthetists in small community hospitals were non-specialists. There were no specialists practicing in any reporting hospital with less than 200 births/year.

As regards the replies from individual physicians, 12 of the 13 non-specialists practiced in hospitals having less than 1000 deliveries/year.

\section{Facilities}

The majority of reporting hospitals appeared to be adequately equipped with piped oxygen, suction and resuscitation equipment (maternal and neonatal) in labour and delivery rooms. However, three community hospitals (all having 201-500 deliveries/year) reported having no emergency cart available for maternal resuscitation. All affiliated hospitals and 87 per cent of community hospitals reported that their delivery rooms were adequately equipped for administration of general anaesthesia for vaginal delivery, but only 66.7 and 48.7 per cent respectively, felt that they were adequately equipped to undertake emergency Caesarean sections in these rooms. It was noteworthy that while 100 per cent of the universityaffiliated and 35.8 per cent of community hospitals were equipped with electronic foetal heart monitors, only 33.3 and 25 per cent respectively had maternal ECG monitors in the obstetric unit. Group $\mathrm{O}$, Rh negative blood was immediately available in only 64 per cent of the community hospitals. This lack was noted mainly in the smaller units, where it might take 30 minutes or longer to obtain blood, even in an emergency (in one case, the delay was stated to be three hours). Post-anaesthetic recovery facilities, in the delivery suite, were present in two (of three reporting) university-affiliated hospitals and in none of the community hospitals. Only one of the two obstetric recovery rooms was staffed by registered nurses with special recovery room training.

Only 15 per cent of the community hospitals had neonatal intensive care units. The hospitals which reported that no such facilities were available, included some having over 1000 deliveries/year.

\section{Physician coverage}

While all the reporting university-affiliated hospitals had anaesthetists in the hospital at all times, in only one was there an anaesthetist assigned to cover the obstetric unit, with no other concomitant duties. None of the community hospitals (including those having over 1000 deliveries/year) reported having continuous "in-house" anaesthesia coverage. In fact, 15 ( 38.5 per cent) of these hospitals had no "on call" facilities available for any physician who might choose to stay in the hospital.

Paediatricians were readily available (either inhouse or on call) in all the university-affiliated hospitals and all had neonatal intensive care units adjacent to the delivery suite. However, in community hospitals, only 11 (28.2 per cent) reported that it was possible to obtain immediate paediatric service in the delivery room. This observation was not completely confined to the smaller institutions, but was also apparent in some of the larger obstetric units.

\section{Preanaesthetic preparation (Table III)}

In this area one encounters major differences, in both attitudes and practice, from those seen in the general operating rooms.

None of the hospitals, nor individual physicians, replying to this portion of the questionnaire, reported a practice of regular, routine visits by an anaesthetist to women in the obstetric suite.

While signed, informed consent for epidural analgesia, during labour, was not generally obtained, the majority of anaesthetists stated that they routinely explain the procedure prior to administration of the block.

Antacids were usually administered prior to Caesarean section, but infrequently during labour. Sodium citrate was the antacid of choice in university-affiliated hospitals, while in community hospitals particulate antacids were more frequently used. However, 14 community hospitals (35.9 per cent) did not answer this question. Metoclopramide and $\mathrm{H}_{2}$-blockers had limited use in a few institutions. 
TABLE III Pre-anaesthetic preparation

\begin{tabular}{|c|c|c|c|c|}
\hline & \multirow{2}{*}{\multicolumn{2}{|c|}{ Hospitals }} & \multicolumn{2}{|l|}{ Physicians } \\
\hline & & & \multirow{2}{*}{$\begin{array}{l}\text { University } \\
\text { Hospitals } \\
(n=19)\end{array}$} & \multirow{2}{*}{$\begin{array}{l}\text { Community } \\
\text { Hospitals } \\
(n=38)\end{array}$} \\
\hline & $\begin{array}{l}\text { University } \\
(n=3)\end{array}$ & $\begin{array}{l}\text { Community } \\
(n=39)\end{array}$ & & \\
\hline $\begin{array}{l}\text { Prenatal visit to anaesthetist } \\
\text { possible and encouraged }\end{array}$ & $100 \%$ & $28 \%$ & N/A & N'A \\
\hline $\begin{array}{l}\text { Routine visit by anaesthetist } \\
\text { to all patients in labour }\end{array}$ & $0 \%$ & $0 \%$ & $0 \%$ & $0 \%$ \\
\hline $\begin{array}{l}\text { Signed informed consent prior } \\
\text { to epidural analgesia }\end{array}$ & $33.3 \%$ & $25.6 \%$ & $47.3 \%$ & $27.8 \%$ \\
\hline $\begin{array}{l}\text { Literature and other patient } \\
\text { teaching aids available }\end{array}$ & $66.6 \%$ & $7.7 \%$ & N/A & N/A \\
\hline \multicolumn{5}{|l|}{ Routine use of antacids } \\
\hline during labour & $66.7 \%$ & $5 \%$ & $31.6 \%$ & $36.1 \%$ \\
\hline before Caesarean section & $66.7 \%$ & $66.7 \%$ & $68.4 \%$ & $91 \%$ \\
\hline \multicolumn{5}{|l|}{ Choice of antacid (when used) } \\
\hline sodium citrate & $100 \%$ & $23 \%$ & $100 \%$ & $58 \%$ \\
\hline particulate & $0 \%$ & $41 \%$ & $0 \%$ & $42 \%$ \\
\hline
\end{tabular}

\section{Vaginal delivery (Table IV)}

Fifteen of the 39 reporting community hospitals did not provide epidural analgesia to women in labour, including the largest unit having $>2500$ births/year. In a few of the remaining 24 , the numbers were very small ( $<1$ per cent) and tended to be single dose injections. A "test dose" to exclude possible intravascular or subarachnoid injections was routinely used in all university hospitals, but in only 19 ( 79 per cent) of the 24 community hospitals. Bupivacaine was the local anaesthetic drug of choice in first stage labour. Lidocaine and mepivacaine were used on occasion, but not 2-chloroprocaine.

All the university hospitals, but only 66.6 per cent of community hospitals stated that there was always a physician in the hospital when epidural analgesia was being used in labour. Of the 57 physicians who replied to the questionnaire, 32 felt that this practice was desirable, but the other 25 ( 43.8 per cent) either felt that it was unnecessary, or gave no opinion.

General anaesthesia - when this technique was required, endotracheal intubation was generally practiced. "Mask" anaesthesia was never used in university-affiliated hospitals and in only three of the reporting community hospitals, for a total of
TABLE IV Analgesia for vaginal delivery (\% range)

\begin{tabular}{lll}
\hline Technique & $\begin{array}{l}\text { University } \\
\text { hospitals } \\
(n=3)\end{array}$ & $\begin{array}{l}\text { Community } \\
\text { hospitals } \\
(n=39)\end{array}$ \\
\hline $\begin{array}{l}\text { Epidural } \\
\text { catheter } \\
\text { single dose }\end{array}$ & $20-40$ & $0-20$ \\
Caudal block & 0 & $0-4$ \\
Spinal (“saddle block") & 0 & 0 \\
Pudendal block & $0-5$ & $0-6$ \\
Paracervical block & $0-23$ & $0-80$ \\
Inhalation analgesia & $0-1$ & $0-5.7$ \\
General anaesthesia & $1-33$ & $0-75$ \\
$\quad$ mask & & $0-4$ \\
endotracheal tube & 0 & $0-15$ \\
\hline
\end{tabular}

0.15 per cent of all vaginal births. In the replies from individual anaesthetists, two specialists and three non-specialists stated that they occasionally administered general anaesthesia for vaginal delivery without endotracheal intubation.

\section{Caesarian section}

Five of the 39 community hospitals reported that they did not do Caesarean sections and these patients were always transferred out. Anaesthetic techniques used are listed in Table $\mathrm{V}$. 
TABLE V Anaesthesia for Caesarean section (\% range)

\begin{tabular}{lcc}
\hline & $\begin{array}{l}\text { University } \\
\text { hospitals } \\
(n=3)\end{array}$ & $\begin{array}{l}\text { Community } \\
\text { hospitals } \\
(n=34)\end{array}$ \\
Technique & & \\
\hline $\begin{array}{l}\text { General anaesthesia } \\
\text { mask }\end{array}$ & 0 & 0 \\
endotracheal intubation & $35-70$ & $20-100$ \\
Epidural block & $29-65$ & $0-50$ \\
Subarachnoid block & $0-1$ & $0-42$ \\
\hline
\end{tabular}

General anaesthesia - Respondents were asked to reply "always," "usually," "occasionally" or "never" to questions regarding generally accepted safe techniques - hydration prior to induction, preoxygenation, cricoid pressure during rapid intubation, displacement of the uterus to avoid aortocaval compression and abdominal prep and draping prior to induction of anaesthesia. While these were all routine practice in the universityaffiliated hospitals, their importance was not consistently recognised in the community hospitals (including some of the larger units) (Table VI).

Thiopentone was routinely used as the induction agent; and the most frequent form of maintenance of anaesthesia, prior to delivery of the baby, was 50 per cent oxygen/nitrous oxide with 0.5 per cent halothane. Enflurane was used with some frequency, but none of the hospitals reported use of methoxyflurane.

Epidural anaesthesia - Only 25 of the 34 reporting hospitals in which Caesarean sections were performed, used epidural anaesthesia. In the other nine hospitals, all their Caesarean sections were done under general anaesthesia. Again they were requested to answer "always," "usually," "occasionally" or "never" to questions regarding commonly accepted practices - administration of oxygen by mask or nasal prongs; rapid intravenous infusion of crystalloid solution prior to insertion of the block; and displacement of the uterus by left table tilt or placement of a wedge under the right hip (Table VII).

The reported incidence of use of 0.75 per cent bupivacaine may possibly have been modified since this survey, in view of the recent concern regarding cardiotoxic effects of this drug. Routine addition of epinephrine to the local anaesthetic agent was not frequent, and the incidence of prophylactic use of vasopressors was 16 per cent in community hospitals and 0 per cent in university hospitals. When vasopressors were required, ephedrine was usually the drug of choice, but a few individual physicians expressed a preference for other agents, such as phenylephrine, methoxamine or metaraminol.

\section{Neonatal resuscitation}

The question was asked, "In your institution, who is primarily responsible for resuscitation of depressed neonates?" All of the university-affiliated hospitals identified this individual as a paediatrician, while in 51.5 per cent of the community hospitals this responsibility was delegated to the family physician (Table VIII). However, in response to the question, "Who do you feel should be the primary resuscitator?" 78.9 per cent of the individual physicians stated "paediatrician."

The physicians were asked whether they felt they could safely take care of both mother and baby. Fifteen and one-half per cent of those in

TABLE VI General anaesthesia for Caesarean section (\% answering "always" or "usually")

\begin{tabular}{|c|c|c|c|c|}
\hline & \multirow{2}{*}{\multicolumn{2}{|c|}{ Hospitals }} & \multicolumn{2}{|l|}{ Physicians } \\
\hline & & & \multirow{2}{*}{$\begin{array}{l}\text { University } \\
\text { Hospitals } \\
(n=19)\end{array}$} & \multirow{2}{*}{$\begin{array}{l}\text { Community } \\
\text { Hospitals } \\
(n=38)\end{array}$} \\
\hline & $\begin{array}{l}\text { University } \\
(n=3)\end{array}$ & $\begin{array}{l}\text { Community } \\
(n=39)\end{array}$ & & \\
\hline Fluid preload & 100 & 70.5 & 100 & 84.2 \\
\hline Pre-oxygenation & 100 & 91 & 100 & 94.7 \\
\hline Cricoid pressure & 100 & 70.5 & 100 & 86.8 \\
\hline Uterine displacement & 100 & 73.5 & 100 & 94.7 \\
\hline Skin prep' before induction & 100 & 88 & $\mathrm{~N} / \mathrm{A}$ & N/A \\
\hline
\end{tabular}


TABLE VII Epidural anaesthesia for Caesarean section (\% answering "always" or "usually")

\begin{tabular}{|c|c|c|c|c|}
\hline & \multirow{2}{*}{\multicolumn{2}{|c|}{ Hospitals }} & \multicolumn{2}{|l|}{ Physicians } \\
\hline & & & \multirow{2}{*}{$\begin{array}{l}\text { University } \\
\text { Hospitals } \\
(n=19)\end{array}$} & \multirow{2}{*}{$\begin{array}{l}\text { Community } \\
\text { Hospitals } \\
(n=38)\end{array}$} \\
\hline & $\begin{array}{l}\text { University } \\
(n=3)\end{array}$ & $\begin{array}{l}\text { Community } \\
(n=25)\end{array}$ & & \\
\hline $\mathrm{O}_{2}$ by mask & 100 & 64 & 100 & 96.7 \\
\hline Flujd preload & 100 & 76 & 100 & 83.3 \\
\hline Uterine displacement & 100 & 68 & 100 & 93.3 \\
\hline Prophylactic vasopressor & 0 & 16 & 10.5 & 10 \\
\hline \multicolumn{5}{|l|}{ Agents } \\
\hline $0.75 \%$ bupivacaine & 33.3 & 12 & 42.1 & 23.3 \\
\hline $0.5 \%$ bupivacaine & 33.3 & 40 & 10.5 & 46.7 \\
\hline lidocaine $\mathbf{H C l}$ & 0 & 16 & 5.2 & 20 \\
\hline lidocaine $\mathrm{CO}_{2}$ & 33.3 & 20 & 52.6 & 36.7 \\
\hline 2-chloroprocaine & 0 & 0 & 0 & 0 \\
\hline mepivacaine & 0 & 4 & 0 & 3.3 \\
\hline Epinephrine added & 0 & 8 & 5.2 & 33.3 \\
\hline
\end{tabular}

university-affiliated hospitals and 31.5 per cent in community hospitals indicated that they felt this was satisfactory.

Each of the university-affiliated hospitals had a written protocol for neonatal resuscitation, but this was true in only eight ( 20.5 per cent) of the community hospitals.

The heart rate of the neonate was routinely monitored in 30 (76.9 per cent) of community hospitals and the body temperature in only 23 (59 per cent).

The individual physicians were asked what they felt the ideal role of the anaesthetist in neonatal resuscitation should be. The replies are summarised in Table IX.

\section{Discussion}

\section{Personnel}

It is apparent that a large proportion of the obstetric

TABLE VIII Primary responsibility for resuscitation of neonate

\begin{tabular}{lcc}
\hline & $\begin{array}{c}\text { University } \\
\text { hospitals } \\
(n=3 !\end{array}$ & $\begin{array}{l}\text { Community } \\
\text { hospitals } \\
(n=39)\end{array}$ \\
\hline Anaesthetist & 0 & $17.9 \%$ \\
Paediatrician & $100 \%$ & $23 \%$ \\
Family physician & 0 & \\
Nurse & 0 & $51.5 \%$ \\
Whoever available & 0 & $5.1 \%$ \\
& & $2.5 \%$ \\
& &
\end{tabular}

anaesthesia service in British Columbia is being supplied by non-specialist anaesthetists (physicians who are not certified as specialists by the Royal College of Physicians of Canada), who may not have received specific training in this area of the specialty. Additionally, many of these people practice in small hospitals where the obstetric case load is too small for them to adequately develop and mainta.n their skills. Some of these institutions are located in remote areas, where consultant or specialist back-up is not available. During the winter months these locations may be isolated and transfer of complicated obstetric patients may be difficult or even impossible. The replies to this survey indicate two problems which need to be addressed: (a) the need for ade-

TABLE IX Perceived ideal role of anaesthetist in neonatal resuscitation

\begin{tabular}{|c|c|c|}
\hline & $\begin{array}{l}\text { University } \\
\text { hospitals } \\
\text { anaesthetists }\end{array}$ & $\begin{array}{l}\text { Community } \\
\text { hospitals } \\
\text { anaesthetists }\end{array}$ \\
\hline Primarily in charge & 0 & $2.3 \%$ \\
\hline $\begin{array}{l}\text { Initiate resuscitation and } \\
\text { hand over to paediatrician }\end{array}$ & $72.2 \%$ & $15.9 \%$ \\
\hline $\begin{array}{l}\text { Responsible for respiratory } \\
\text { and circulatory problems and } \\
\text { paediatrician everything else }\end{array}$ & $16.7 \%$ & $11.4 \%$ \\
\hline $\begin{array}{l}\text { Standby, with paediatrician } \\
\text { in charge }\end{array}$ & $11.1 \%$ & $70.4 \%$ \\
\hline
\end{tabular}


quate training in obstetric anaesthesia and definition of a minimum, mandatory training period; (b) provision of opportunity to update knowledge and maintain skills. The University of British Columbia, in common with many other universities in Canada, now provides a training programme in anaesthesia for family physicians. This program includes a mandatory period of one month at the provincial tertiary care obstetric hospital, with a case load of some 7500 deliveries/ year. Consideration is being given to increasing the training period for family physician/anaesthetists from the present six months to one year; and increasing the exposure to obstetric anaesthesia from one to two months.

With regard to the second problem, in British Columbia a non-specialist anaesthetist is able to retum to the obstetric hospital for a period of one month and work full-time in the anaesthesia department. In the case of specialists who request a "refresher" visit, they are encouraged to take advantage of the clinical traineeship awards offered by the Royal College of Physicians and Surgeons of Canada. However, it is often not practical, nor even possible, for a physician to take time out from practice to spend in a teaching institution. Regular visits to community hospitals by teams, consisting of anaesthesiologists, obstetricians and paediatricians, would be an efficient method of providing clinical updating and would allow for identification of specific problem areas in each hospital visited. Standards of competence required from anaesthetists in their regular practice should also be expected in the case of obstetric procedures. ${ }^{4,5}$

\section{Facilities}

Generally, anaesthetic and resuscitation equipment in obstetric suites seemed to be adequate. However, in many obstetric units, more importance appeared to be attached to foetal monitoring equipment than to devices for maternal cardiac monitoring.

The authors have a concern over the almost universal lack of facilities for post-anaesthetic recovery and trained recovery room nursing personnel in obstetric suites. It is recognized that, at least in some units, the small case load makes it difficult to justify the expense of maintaining such a recovery room, especially when the surgical recovery room is easily accessible. However, in the larger units, the omission of these facilities is more difficult to justify, on the grounds of safe clinical practice.

\section{Physician coverage}

In none of the reporting community hospitals was there any "in house" anaesthesia coverage; and even in the university-affiliated hospitals, with continuous anaesthesia coverage in the hospital, all but one stated that there was no anaesthetist assigned specifically to cover the obstetric unit. At least part of the reason for this deficiency (except for the smallest obstetric units where it is difficult to justify keeping an anaesthetist constantly available for a very limited case load), would appear to be lack of funding for this service. It is also noted that many (38.5 per cent) of the reporting hospitals had no "on call" facilities for anaesthetists who might wish to remain in the hospital.

Cardiotoxic and other complications of epidural anaesthesia may be delayed in onset. For this reason it is felt that whenever epidural analgesia is being employed, a physician, trained and prepared to recognise and treat the effects of local anaesthetic toxicity (including cardiopulmonary resuscitation), should be present in the hospital and immediately available.

\section{Preanaesthetic preparation}

While the Canadian Anaesthetists' Society recognises the importance of pre-anaesthetic assessment and preparation, ${ }^{4}$ it is apparent that the standards which are accepted for operating rooms are not generally applied in obstetric units. It appears to be the exception rather than the rule for a parturient to be visited by an anaesthetist (other than those scheduled for elective Caesarean section). Prenatal visits to anaesthetists, for counselling or consultation, are routinely encouraged only in the university-affiliated hospitals.

While signed, informed consent for epidural analgesia is not frequently obtained, more than 75 per cent of the anaesthetists stated that they routinely explain the procedure to the patient, prior to administration of the block.

Antacids were commonly administered during labour in university-affiliated hospitals but uncommonly in the community hospitals. This preventive measure was more frequently utilised in preparation 
for Caesarean section. The particulate antacids were still being used in many of the community hospitals. There is evidence to suggest that particulate antacids themselves, can cause pneumonitis, with persistent areas of lung consolidation. ${ }^{7}$ Metoclopramide, which has been shown to be effective in reducing gastric volume ${ }^{8}$ without adverse effect on the neonate ${ }^{9}$ and the $\mathrm{H}_{2}$-receptor blockers (cimetidine and ranitidine), which effectively raise gastric $\mathrm{pH},{ }^{10}$ were not being commonly employed at the time of this survey. It is recognised that the use of these agents in obstetric practice is still somewhat controversial.

\section{Vaginal delivery}

As expected, epidural analgesia was not universally available to parturients. However, what was unexpected, was the finding that the lack of availability of this form of labour analgesia was not confined to the small institutions.

General anaesthesia was not commonly administered for vaginal birth. With very few exceptions, endotracheal intubation was a routine part of general anaesthesia. In only three community hospitals was anaesthesia ever administered via a face mask and these cases amounted to only 0.15 per cent of all reported vaginal births.

In our previous survey of Canadian university departments of anaesthesia ${ }^{2}$ we reported an incidence of "mask anaesthesia" of two per cent for vaginal deliveries in university-affiliated hospitals. This figure was similar to that reported by Hicks et $a l .{ }^{1}$ in obstetric anaesthesia training centres in the U.S.A. Hew et al. ${ }^{3}$ in their Toronto survey, did not report on the number of general anaesthetics administered via face mask, but stated that "eleven per cent of anaesthetists at university-affiliated hospitals and 54 per cent in community hospitals sometimes conducted general anaesthesia without tracheal intubation in obstetric patients."

Late pregnancy and labour are often associated with delayed emptying of the stomach (with the frequent presence of solid foodstuff), loss of integrity of the lower oesophageal spincter and lowered $\mathrm{pH}$ of gastric contents. When general anaesthesia is required for the obstetric patient, intubation with a cuffed endotracheal tube with associated cricoid compression until the cuff is inflated is essential.

During the 1976-78 triennium there were 30 maternal deaths in England and Wales directly attributable to anaesthesia. ${ }^{6}$ Eleven of these deaths were due to pulmonary aspiration of gastric contents; and in another three cases "this was most probably the event leading to death."

It is recommended that every institution (indeed, every anaesthetist) should have an established drill for dealing with cases of failed or difficult intubation. Something which has proved to be of value in our institution is a "trouble box," which is a metal container with easily removeable trays (such as a fishing or tool box), containing seldom-used items which may be required to facilitate endotracheal intubation or maintain ventilation in difficult subjects. This box is clearly marked and readily available in the anaesthetizing area.

\section{Caesarean section}

General anaesthesia - It was noteworthy that all hospitals as well as individual anaesthetists reported routine endotracheal intubation when Caesarean sections were done under general anaesthesia. However, in community hospitals 29.5 per cent of cases were induced without cricoid compression; and 26.5 per cent did not have the uterus displaced to relieve compression of the abdominal aorta and inferior vena cava. Anaesthetists need to be aware of the importance of these procedures.

Epidural anaesthesia - There has been an increase in the number of Caesarean sections done under epidural anaesthesia, not just in the large, university-affiliated institutions but also in smaller community hospitals. In this survey the university hospitals reported the use of this technique in 29-65 per cent of cases, while in community hospitals the range was 0-50 per cent. In 1976, Hicks et al. ${ }^{1}$ reported the use of epidural anaesthesia for Caesarean section in only three per cent of cases in all maternity units in the U.S.A. (A.C.O.G. survey, 1970) and 32 per cent in obstetrical anaesthesia training centres. Our survey in $1980^{2}$ found that this technique was employed in 28.2 per cent of Caesarean sections in Canadian universityaffiliated hospitals.

Intravenous fluid preload with non-dextrose containing crystalloid solution (to reduce the incidence of hypotension), uterine displacement (to avoid aortocaval compression) and oxygen by face mask are accepted safe practices, but it would appear that the importance of these procedures was 
not uniformly recognised in the community hospitals. The fact that 36 per cent of cases did not receive a fluid preload and 32 per cent did not have the uterus displaced, may possibly be related to the reported prophylactic use of vasopressor drugs in 16 per cent of cases.

\section{Neonatal resuscitation}

In the majority of community hospitals it was not possible to get immediate paediatric help in the delivery rooms. It should also be recognised that not all paediatricians are skilled at resuscitating depressed neonates. This responsibility was usually delegated to an anaesthetist if one was present. However, in more than 50 per cent of the reporting community hospitals, the person primarily responsible for the neonate was the family physician. This practice raises two concerns:

(a) Whether this person is able to continue to attend to the needs of the mother while having to give attention to a depressed neonate;

(b) Whether family physicians who practice obstetrics should be required to demonstrate competence in neonatal resuscitation. The question then arises regarding the availability of facilities for initial training and for maintaining their skills.

When an anaesthetist is considered to be responsible for resuscitation of a depressed neonate, the same dichotomy arises. In the period immediately after delivery, the mother generally requires the attention of the anaesthetist, especially if a general anaesthetic is being administered. We note that 15.5 per cent of the anaesthetists in university-affiliated hospitals and 31.5 per cent in community institutions stated that they felt comfortable caring for both mother and baby.

The number of institutions reporting that the neonatal heart rate and temperature were not routinely monitored is of concern. It is also noted that only one-fifth of the community hospitals had a written protocol for neonatal resuscitation.

We suggest that in those institutions which do not have readily available paediatric service the delivery room nurses should be trained at least to initiate resuscitation of depressed neonates. We also feel that a demonstrated skill in newborn resuscitation should be a requirement for granting of obstetric privileges in those hospitals where specialist services are deficient. We would also refer to our earlier suggestion of teams (anaesthe- tist, obstetrician and neonatologist) making regular visits to community hospitals for purposes of educational updating and rendering advice regarding clinical practice and facilities.

\section{References}

1 Hicks JS, Levinson G, Shnider SM. Obstetric anesthesia training centers in the USA - 1975. Anesth Analg 1976; 55: 839-45.

2 McMorland GH, Jenkins LC. A survey of obstetri$\mathrm{cal}$ anaesthesia practice, teaching and research in Canadian university departments of anaesthesia. Can Anaesth Soc J 1980; 27; 417-21.

3 Hew EM, Rolbin SH, Cole AFD, Virgint S. Obstetrical anaesthesia practice in the University of Toronto affiliated hospitals and some randomly selected community hospitals. Can Anaesth Soc J 1981; 28: 158-66.

4 Committee on Standards of Practice of the Canadian Anaesthetists' Sociery. Guidelines for the Basic Standards of Practice of Anaesthesia (1981).

5 Joint Commission of Accreditation of Hospitals. Accreditation Manual for Hospitals. Chicago (1973).

6 Report on Confidential Enquiries into Maternal Deaths in England and Wales 1976-1978. Her Majesty's Stationery Office, 1982. Pages 77-87.

7 Gibbs CP, Schwartz DJ, Wynne JW, Hodd CJ, Kuck $E J$. Antacid pulmonary aspiration in the dog. Anesthesiology 1979; 51: 380-5.

8 Howard FA, Sharp DS. Effect of metoclopramide on gastric emptying during labour. $\mathrm{Br}$ Med $\mathrm{J}$ 1973; $1: 446$.

9 Bylsma-Howell M, Riggs KW, McMorland GH et al. Placental transport of metoclopramide: assessment of maternal and neonatal effects. Can Anaesth Soc $J$ $1983 ; 30 ; 487-92$.

10 Hodgkinson R, Glassenberg R, Joyce TH III, Coombs DW, Ostheimer GW, Gibbs CP. Comparison of cimetidine $\left(\right.$ Tagamet $^{R}$ ) with antacid for safety and effectiveness in reducing gastric acidity before elective cesarean section. Anesthesiology 1983; 59: 86-90. 


\section{Résumé}

Les hôpitaux et les anesthésistes de la Colombie Britannique ont été étudiés au moyen de questionnaires, afin d'évaluer leur mode de pratique de l'anesthésie obstétricale, les qualifications et le nombre du personnel, les facilités obstétricales dans les hopitaux ainsi que les facilités et les protocoles pour la réanimation des nouveaux-nés.

Il était évident qu'en grande partie les services d'anesthésie obstétricale dans cette province étaient formés par des médecins qui n'étaient ni entrainés ni certifiés comme spécialiste en anesthésie.

L'évaluation pré-anesthésique dans les unités d'obstétriques différait en attitude et pratique, des normes qu'on attendaient des salles d'opération en générale. Il y avait aussi dans les hôpitaux communautaires une incidence significative de médecins ne suivant pas les normes de pratique sécuritaire acceptées (dans les services d'obstétrique), tel que l'apport liquidien préinduction, l'oxygénation, la pression cricoidienne, durant l' intubation et la prêvention de la compression de l'aorte et de la veine cave. Cependant, l'administration de l'anesthésie générale sans intubation endotrachéale a été un phénomène rare dans cette enquête.

Les salles de réveil, dans les unités obstétricales, étaient particulièrement absentes, même dans les grands hôpitaux.

La majorité des hôpitaux communautaires n'avait pas de protocoles établis pour la réanimation des nouveauxnés; et le nombre d'institutions qui ont rapporté que la fréquence cardiaque du nouveau-né ainsi que sa température n'étaient pas surveillées de routine était inquiétant.

Il est recommandé que les normes minimums pour l'entrainement en anesthésie obstétricale doivent être clairement définies; d'autre part une considération doit être faite afin de revoir et d' améliorer les connaissances et les aptitudes des médecins pratiquant l'anesthésie dans les petits hôpiraux communauraires. 